\title{
Change Processes in School-Based Humanistic Counselling
}

Abstract: Background: Recent research has indicated that school-based humanistic counselling ( $\mathrm{SBHC}$ ) is effective for young people in reducing psychological distress and facilitating achievement of personal goals. However, the processes by which this form of counselling brings about change are not yet understood.

Aim: This study aims to clarify the dynamic processes of change that young people go through when they attend $\mathrm{SBHC}$, in order inform school counselling practice, training and further research.

Method: This is a qualitative interview study with 14 participants who had recently completed between two and ninw sessions of SBHC as part of a randomised controlled trial (RCT). Interviews were transcribed and analysed using a grounded theory approach resulting in the development of five change process models.

Results: Multiple change processes were evident for individual clients, and were labelled relief, increasing self-worth, developing insight, enhancing coping strategies and improving relational skills.

Implications: The data indicates that multiple pathways of change are possible, and that change processes associated with different theories of personality change are not mutually exclusive. The study is limited by a small, selective sample and low testimonial validity, and further qualitative research is needed to understand change processes in SBHC more fully. 


\section{Change Processes in School-Based Humanistic Counselling}

Counselling provision is universal in post-primary schools in Northern Ireland and secondary schools in Wales (Cooper, 2013), but in Scotland and England varies widely between regions (Hanley, Barlow, Humphrey, Jenkins \& Wigelsworth, 2012). However, in England, the issue of access to counselling in schools is gaining political prominence. The Department for Education (2015, p.11) in the UK has now published advice on counselling in schools. This builds on the Department of Health and NHS England's (2015) strategy for child mental health, Future in Mind, and includes the 'strong expectation' that 'over time all schools should make counselling services available to their pupils.'

Little is known, however, about the processes of change that young people may go through in school-based counselling. Understanding this process is important in being able to identify the particular young people, or situations, in which school-based counselling may be most helpful. It is also essential for the development and refinement of the intervention. Research has been conducted on the helpful aspects of school-based counselling, as well as the particular outcomes that school-based counselling might bring about. This may shed some light on the beginning and end points of the change processes.

A recent qualitative meta-analysis of helpful factors in school-based counselling (Griffiths, 2013) found that the most commonly identified factor was 'having an opportunity to talk/express self openly/be listened to'. Other meta-categories of helpful factors identified in this study were 'client-led process/other client related factors', 'counsellor's strategies/ suggestions/guidance/advice', 'release of tension/getting things off one's chest/positive experience', 'feeling understood/accepted/not judged', 'someone being there for them who is independent/new perspective', 'counsellor's personal qualities', and 'confidentiality/privacy'. 
Data on the specific positive outcomes for school-based counselling (as reported by clients) are available from a number of studies. In terms of clinical outcomes, Cooper (2009) reports on types and domains of change using data from the five subscales of the Strengths and Difficulties Questionnaire (SDQ) ( $k=6$ studies) and data from the impact supplement of the SDQ ( $k=5$ studies). These suggested that the largest improvement was on the Emotional Symptoms subscale (mean effect size, $E S=0.59$; Cooper, 2009). Smaller positive changes were shown on the subscales relating to Conduct Problems (mean $E S=0.34$ ), Hyperactivity (mean $E S=0.36$ ) and Peer Problems (mean $E S=0.34$ ). Data from the SDQ impact supplement showed that the largest improvements were in the domain of friendships (mean $E S=0.47)$ and home life (mean $E S=0.41)$.

In terms of clients' perceptions of positive outcomes, Lynass et al. (2012) thematically analysed 11 semi-structured interviews with young people at the end of a period of schoolbased counselling which included data on specific changes reported by participants. Emerging themes revealed that the most commonly reported change was being seen differently by others ( $n=9$ clients). This was followed by talking about feelings more easily, improvements in school, more confident/increased self-esteem and changed thinking/ different perspective ( $n=7$ clients each). Other commonly reported positive changes were feeling happier, improved relationships with friends and standing up for self more $(n=6$ clients each).

Finally, two UK studies have looked specifically at the impact of school-based counselling on young people's academic achievement (Ogden, 2006; Rupani, Haughey \& Cooper, 2012). These studies suggest that school-based counselling can have a positive impact on young people's ability to concentrate, participation in class, and confidence in relation to school work. In addition, Cooper's (2009) meta-analysis showed that 
approximately two thirds of clients reported improvement in this area, and in Lynass et al.'s (2012) thematic analysis of post counselling interviews 'improvements in school' emerged as an outcome.

Research to date, therefore, suggests that young people experience a range of factors as helpful in school-based counselling, in particular talking through their problems; and that this can lead to a range of positive outcomes, particularly in the emotional and interpersonal domain. This is consistent with a broadly pluralistic perspective (Cooper \& McLeod, 2007, 2011), which suggests that counselling and psychotherapy may be helpful through a multiplicity of change processes.

The aim of this study is to look, more specifically, at what these changes are in school-based counselling. To do so, we focus on one form of school-based counselling: school-based humanistic counselling (SBHC). This is a standardised form of the personcentred/humanistic approach that is widely used in UK secondary schools (Cooper, 2009; Hill et al., 2011). SBHC is grounded in evidence-based competences for effective humanistic counselling (Roth, Hill \& Pilling, 2009), subsequently adapted for use with young people (Hill, Roth \& Cooper, 2014). It has been shown to significantly reduce young people's levels of psychological distress and facilitate the attainment of their personal goals (Cooper et al., 2010; McArthur, Cooper \& Berdondini, 2013; Pybis et al., 2014).

\section{Method}

This was a qualitative interview study using an inductive approach (i.e. data-driven, not theory-driven). The design is informed by grounded theory (e.g. Glaser \& Strauss, 1967; Glaser, 1978), combining elements of a phenomenological approach with those of a hermeneutic approach in an iterative cycle. Through close engagement with interview 
transcripts and a repetitive cycle of checking between data and emerging theory, this study aims to develop trustworthy hypotheses regarding potential pathways to positive change for young people in SBHC.

Interview data was collected as part of a pilot randomised controlled trial (RCT) comparing school-based humanistic counselling (SBHC) to waiting list conditions (McArthur, Cooper and Berdondini, 2013). Interviews from those participants allocated to the SBHC condition were transcribed and analysed for the purposes of the current study.

Therefore, analysis did not occur in parallel with data collection, as is traditionally the case in a grounded theory approach (McLeod, 2001; Glaser \& Strauss, 1967).

Due to space constraints, this article deals solely with positive change processes developed from helpful aspects and positive outcomes reported by young people. Analysis of similar data on unhelpful aspects and negative outcomes exploring the mechanisms of hindering processes in SBHC will be published separately.

\section{Participants}

Interviews were analysed from 14 young people who were allocated to the counselling intervention of the RCT. Table 1 lists participants, identified by pseudonyms, and includes information on gender, age, number of counselling sessions attended, and school. All participants were Caucasian, and two considered themselves to be disabled. Eligibility criteria for participants in the RCT are detailed in McArthur, Cooper and Berdondini (2013) including capacity to give informed consent and a score of at least 5 on the Emotional Symptoms subscale of the Strengths and Difficulties Questionnaire (SDQ-ES; Goodman et al., 1998). Participants will hereafter be referred to as 'clients'. 


\section{Data collection}

The Client Change Interview (Elliott, 1999) was developed for use with clients, and asks about their experiences of changes since beginning therapy and any helpful and hindering aspects of the therapy process. This tool was adapted for use with young people by Lynass et al. (2012), and this was the version used in the present study.

Each of the questions was used as a starting point, and interviewers had flexibility to explore related areas of experience raised by the client. Follow-up questions included those designed to explore clients' change attributions, in other words, any theories regarding the reasons for changes they had reported. However, in line with guidelines for good practice in qualitative inquiry (e.g. Stiles, 1993; Elliott et al., 1999), the focus of each interview was on clients' descriptions of their experience as opposed to explanations.

Of the 14 interviews analysed, eight were conducted by an independent researcher, and six by the first author. All interviewers were trained in counselling and/or qualitative interviewing skills.

\section{Procedure}

Clients attended between two and nine counselling sessions each (mean 6.6) with one of three female counsellors trained to Masters level. Semi-structured interviews were conducted approximately 12 weeks after clients began counselling.

The counselling intervention was designed to adhere to specific competences for humanistic therapy developed by Roth et al. (2009). These are based on person-centred principles such as communicating empathic understanding and maintaining a nonjudgemental attitude. However, counsellors were encouraged to work according to their own personal style, preference and expertise within the confines of these competences. In other 
words, the intervention was manualised according to broad humanistic principles and personcentred attitudes, as opposed to providing a concrete directive for the counselling. Therefore, the moment-to-moment practice of therapy was determined to a large extent by the individual counsellor. An example of this is that one of the counsellors provided materials such as word cards and differently shaped stones in order to introduce activities to facilitate the client's process.

\section{Ethical considerations}

Clients gave informed consent and their parents/guardians were made aware of the study with the opportunity to opt out. Interviews were recorded on encrypted data files, and pseudonyms have been used here to protect confidentiality. Ethical approval was obtained from the relevant University Ethics Committee.

\section{Analysis}

The analysis was specifically informed by the illustration of grounded theory given by Rennie, Philips \& Quartaro (1988), and its application in Rennie's (1990) study of clients' experiences of therapy. Verification steps (Elliott et al., 1999) were taken at every stage of the analysis, reviewing the data and subsequent interpretations for errors. This analysis was undertaken by the first author, and $10 \%$ of the resulting categories were cross-checked by the second author before process models were developed by the first author.

\section{Meaning unit extraction}

By close reading each transcript in turn and selecting every client utterance potentially relevant to counselling, 'meaning units' were extracted. Rennie et al. (1988), describe 
meaning units as 'individual concepts conveyed by the interviewees' (p.142). In this case, meaning units comprised the client's actual words, with none added by the first author.

\section{Interpretation}

Each transcript was re-read to extract 'interpretive statements', which are single concepts taken from the author's interpretation of the participants' words in context. Interpretive statements often employed terms not used by the client, for instance 'more present in conversation with Mum' or 'growth in sense of agency'. The two types of analytic unit extracted reflect an attempt to combine elements of a phenomenological approach (meaning units entirely in the words of the client) with those of a hermeneutic approach (interpretive statements emerging from the researcher's understanding), consistent with grounded theory which aims to integrate both.

\section{Categorisation}

The process of developing categories involved grouping and re-grouping meaning units several times while re-reading transcripts, descriptive summaries and interpretive statements. Two domains were selected to form the body of the change process analysis: helpful factors and positive changes, shown in Table 2. A further two domains, hindering factors and negative changes were analysed separately to develop potentially unhelpful processes (the full taxonomy is available in author citation). For each category, the number of respondents who made utterances related to this concept is listed with the total number of meaning units making up the category.

\section{Developing process models}


Change process models were developed where there was evidence of links between helpful factors in counselling and positive changes. Trends emerging from this set of categories were considered in parallel to transcripts, and potential process models were developed by making connections between categories across clients. Each client's process was reviewed thoroughly with reference to the interview as a whole and the categorisation of meaning units extracted from it. These process models were then tested against each interview and revised accordingly, as part of the ongoing iterative process comparing data with emerging theory.

\section{Reflexive statement}

The authors are humanistic counsellors involved in school-based counselling research and therefore may be biased towards processes of change that reflect humanistic theory. The analysis was fuelled by curiosity and desire to understand clients' experiences as accurately as possible. With this goal in mind, preconceptions were bracketed and a systematic datadriven approach was taken in the hope of representing clients' words with minimal bias.

\section{Results}

The following five processes of change were developed from the data: relief, increasing selfworth, enhancing coping strategies, insight and improving relational skills. Table 1 shows the change processes identified for each client. Specific outcomes were not confined to one pathway of change; rather, the same outcomes were achieved in different ways by different clients. 
For 12 clients, talking about emotions led directly to relief, most often from anxiety or anger. Clients described a build-up of emotion which wasn't expressed, but was dissipated by talking openly to the counsellor: 'when you've spoke about it you feel better because you've finally got it out and told someone how you feel' (Hannah); 'I just kind of build up and I just want to get it out, and [talking] does get it out, it's good' (Dylan). This was linked to the suggestion that talking openly about emotions was something that clients wouldn't be able or willing to do otherwise: 'just being able to tell somebody about stuff, instead of keeping it, that helps as well' (Kimberley); 'you talk in a way that, you know, you don't normally talk to people' (Chloe); 'you couldn't do that with a teacher, you couldn't sit with a teacher and talk about things like that...I think it's good like that, you can come in and be able to talk to somebody' (Paul).

It seems that this catharsis was enough for some clients to meaningfully reduce problematic emotions: 'I got to talk about my anger...now I've not been angry with anybody' (Josh); 'feeling down and stuff, it wasn't as intense as it was...it was actually really good just to sit and talk about how you're feeling' (Dylan). There were several positive outcomes associated with this process. For some clients, relieving worries by talking about emotions in counselling led to better sleep: 'I'm happier to go to bed...it's easier to relax, and I don't know, it feels like I'm not as worried' (Chloe). Relieving distress associated with negative emotions also tended to lead to better focus and concentration, which some clients reported being linked to an improvement in their school work: 'I wasn't really concentrating, but now I am' (Beth); 'I think it helped me concentrate more, and I was able to communicate better with the teachers in school' (Ian). Relief from anger was also associated with improvements in behaviour: 'I'm not getting suspended and all that any more...because I'm not fighting'(Josh). These changes also led to improvements in relationships, both with 
friends and peers: 'I would get angry and start arguing and cause fall outs and it would make me upset...but now I'm sort of taking a back seat, and being able to control that' (Hannah); and with family members: 'at home my behaviour's changed, and I'm getting closer to [Mum and Dad]' (Paul).

\section{Increasing Self-worth}

The process of increasing self-worth was evident for eight clients. Talking about emotions was central, as in each of the other processes, but crucial to this process was the counsellor's response, mainly in terms of attitude. This included listening, understanding, accepting and valuing the client and their point of view: 'she didn't judge me, and listened to what I had to say' (Stuart); 'I got positive feedback, that helped' (Ian); 'someone that listens to me and doesn't...like understands, and doesn't have angry about them' (Rachel).

In response to this, the client entered a cycle of evolving self-esteem, self-efficacy, confidence and agency: 'I like the way the counsellor asks how I feel, all the attention is on me...it's boosted my confidence a lot' (Paul). This had several different impacts for clients, and for Chloe, who had suffered a stroke two years earlier, was linked to improving her mobility: 'I feel kind of just better about myself'; 'I can walk a couple of wee steps on my own'; 'I've got my exercises, I'm meant to do that'; 'I think now I'll probably make more of an effort'. Chloe seemed to become more motivated to work towards the things that she wanted in life after counselling. At the beginning she had set herself a goal of 'taking part in things', and later described how she had changed her attitude to joining a choir, something she had expressed an interest in before: 'I think I've got a more positive outlook since the counselling'; 'I could never sing...I love it, but I just can't sing'; 'but I don't know, now I've kind of opened up a wee bit to myself and I'm sort of thinking...maybe'. For some clients, 
this impacted on their openness with other people: 'my confidence...like I feel much better and not as nervous as I was before...I'm starting to sit with my pals at lunchtime' (Beth, who had told the author at the outset that she often ate her lunch alone through shyness); 'people I didn't really talk to, I've started talking to more' (Ian).

For some clients, the process of increasing self-worth impacted on their school work. Often this related to increased self-efficacy and agency 'I can work better in school when I try' (Paul); and self-esteem 'I used to have thoughts like "I'm just going to end up failing this"... [counselling] made me work harder and try and achieve more, and try and not be, you know, a failure that I thought I was at the start' (Stuart).

For some clients the process of increasing self-worth was pivotal in terms of changing their way of relating to others. Stuart described how this process had impacted on his friendships: ‘[counselling] kind of increased my self-esteem really, and I realised I'm not as bad as I think I am', 'before this thing I had friends, but they did stuff like talk behind my back', 'now I've got proper friends', 'because negative attitude was something that kept me back from making good friends'. Rachel defined confidence specifically in terms of making contact with her Dad: 'I did enjoy [counselling], because she kind of gave me confidence, like I even got my Dad's phone number and called him', 'I'm glad [I decided to have counselling] because I would never have had the confidence to call my Dad'.

Kimberley, who started counselling feeling unhappy with how things were at home, described a powerful impact on her family relationships as part of this process: 'I feel way different, I feel noticed now', 'it's because I've been able to talk to my Mum and Dad', 'I think I have more fun with [Mum], I've got the courage to ask if we're allowed to play this game or that game'. Kimberley specifically noted the counsellor's respect for her autonomy, 'she gave me a choice whether to talk or do some activities', and particular activities which 
made her feel more confident, '[the counsellor] came in with cards once, to describe myself... and it actually made me feel better because there were quite a lot of positives even though I was looking for negatives'. Kimberley described a change in her parents' attitude to her: 'I used to have to do a lot of things, my Mum and Dad didn't ask me if I wanted to do them, they'd just tell me', 'I still have responsibility, but it's just they ask me, and don't force me', 'instead of “[Kimberley], get that!", [Dad] wouldn't shout it at me, he'd turn round and ask me'. Elaborating on this change, Kimberley concluded that her improved ability to express herself resulted in her parents understanding her needs to a greater extent: 'I think being noticed more is generally because I've been able to talk more, so [Mum and Dad] have probably took my point of view and like...made me feel how they might want to feel'.

\section{Insight}

For seven clients, talking about emotions led to reflection, which was often, but not always, linked to specific activities suggested by the counsellor. Insights led to self-awareness and more understanding of others, and often to the previously identified virtuous cycle of selfesteem, self-efficacy, confidence and agency. For some clients, activities helped them to understand their family relationships, such as Rachel and her relationship with her Dad: 'I never even thought of my Dad until I started talking to [counsellor]', 'we use little pebbles and we make a family, and make up a story about them', 'I made one for my Dad, and we went from there'. Describing a similar activity using stones to represent family members, Kimberley said 'when I'd finished I realised everyone was quite close...eventually it just all came to one corner because I was there, and it was like they were all dead special to me. I didn't actually realise that until I done it, so that helped me'. 
Other clients used insights to understand their relationships with friends and peers, like Hannah: 'having someone outwith the situation to talk to, they don't have to take sides, so it's just good', 'now I'm seeing there's no point in arguing', 'I think my friends are even noticing that'. For Chloe, developing self-awareness and understanding of others impacted on her relationships: '[counselling] made me think more about things, and sort of realise more things about myself', 'it's like I can understand people more, it's better'. She also spoke about a specific friendship that had been bothering her, and how her attitude to it had changed 'I've just sort of realised what [friend] is, it's like I can see now', 'I think that friendship's kind of grown apart, and I don't mind'.

For some clients, insights and understanding included developing a more positive perception of other people, either generally, or in relation to significant others. Stuart reported a more positive view of his family, '[counselling] kind of got me trusting my parents more and being able to talk to them more about stuff like problems that are going on'; his friends, 'it's like seeing my friends actually supporting me if I ever need anything'; the teachers at school, 'the teachers are starting to believe in me properly'; and people in general 'people are different, they're more kind hearted'.

Michael described a change in his attitude to his Mum: 'I didn't used to talk to her, I didn't used to like her that much', 'I was going to move in with my cousins, but that would have just passed the problem on', 'you need to get on with your Mum'. When asked if anything had changed for him, he said, 'just being able to go home and actually have a conversation with [Mum]', 'I would have just went up to my room, got ready, and said I was going out, but now I can go in, sit down, take my jacket off'. Often the changes described in clients' relationships involved more mutual caring, as with Michael and his Mum: 'because I 
told my Mum about [counselling], she's been trying to help me as well', 'when I go out, I pop back in to see if she's alright'.

As well as increasing self-awareness and understanding of relationships, Chloe described a more general process of developing insight and empathy. She said 'I think on the whole, [counselling] was a really good experience to have, because it broadened my horizons', 'you think more about, like, who you are', 'it's good to think about what goes through other people's minds', 'since I started...I'm starting to properly understand, and not think about just me as much, think about like, other people, and...I don't know, it's quite a big thing'.

\section{Enhanced coping strategies}

The enhancement of coping strategies was evident for four clients. In this change pathway, clients' talking about their emotions led to specific input from the counsellor, often in the form of relaxation techniques or coping mechanisms. This led directly to an improved ability to cope with emotions, often anger specifically. Josh spoke about being able to cope with angry outbursts, by taking the counsellor's advice: 'I got somebody to talk to, and I don't know, she told me what to do if something went wrong', 'if I was to be in a fight, I was just to like go away somewhere else'. Similarly, Paul described a new approach to his anger which makes use of the counsellor's advice: 'I've been able to cope with my anger a bit better', '[counsellor] says if I feel it go from green, amber to red, then amber is when you know you're about to...', 'it's helped because I know when to calm down in a situation'. He went on to say 'I can feel it when I'm about to... if it's in school, I'll go out of class, say "Miss, can I go outside and take a breather?" or something'. 
Stuart reported being able to handle emotions more generally, linking this outcome to the counsellor's advice: 'she gave me the best advice', 'I've been able to handle more stuff and react in a better way than I used to react', 'just learned how to really handle emotions well, so [counselling] helped'. Neil also described coping with emotions by making use of advice from the counsellor: 'I've been taught how to deal with it', 'now I know how to deal with it and it's easier for me'.

\section{Improved relational skills}

In the process of practising relational skills, which was evident for three clients, the experience of talking openly about emotions with the counsellor led to more open relating with others, both in terms of talking and listening. Clients had the opportunity to practise these communication skills with the counsellor, which led to better communication with others. Beth reported that after counselling, she found it easier both to open up to people and to take in what they were saying to her: 'when I first had [counselling], I was slightly nervous, but I've got a bit better at it', 'I feel much better and not as nervous as I was before', 'I'm sort of getting to really understand my teachers, I know what the teacher's talking about'.

For Paul this led to improvement in his school work, and overlapped with his growing confidence: 'I'm a bit scared about talks in English, last year I got a note for my talk because it was hard to do in front of the class because of my confidence and stuff', 'being in talking to [counsellor], my confidence, it's helped me as well', 'I was scared to talk to anyone, so it's boosted my confidence a lot'.

Kimberley noticed a change in her listening skills: 'my Mum actually noticed that I listen more...I didn't actually realise it at first, but I was getting every word she was saying...I 
used to blank out in a little dream or something'. She attributed this new skill to the counselling, saying 'it's made me listen more, because what [counsellor] was saying, obviously I was listening to that, so it's like helped me learn to listen more'. In response to a question about the impact of talking in counselling, Kimberley also mentioned an instance where she was able to comfort her aunt: 'she looked quite sad, so I was cheering her up. That was what [talking in counselling] done, because we were talking about me cheering up and cheering other people up'.

\section{Discussion}

The helpful factors which emerged from this data support previous findings from schoolbased counselling research (Griffiths, 2013). Talking about emotions has frequently been highlighted as a helpful factor in previous research, as has counsellor listening and understanding (Lynass et al., 2012; Cooper, 2004), advice and specific techniques (Bondi et al., 2006; Cooper, 2004).

Pathways to change shown in this study were varied and overlapping. Relief resulting from talking about emotions, especially anger and anxiety, was the most commonly experienced process. One of the outcomes linked to this process was improvement in school work, which is in line with the link between stress and impaired ability to learn (Schwabe \& Wolf, 2010; Kovacs, 1997), and has previously been demonstrated as a benefit of schoolbased counselling (e.g. Rupani et al., 2012; Ogden, 2006). The process of increasing selfworth, which in this study is conceptualised as a combination of self-esteem, self-efficacy, confidence and agency, is theoretically similar to empowerment, which has been shown to be significant in humanistic therapy with adults (e.g. Timulak, 2007), and is arguably an even more salient issue for young people (Christens \& Peterson, 2012). In this study, increasing 
self-worth was hypothesised to result primarily from the counsellor's valuing attitude towards the client, and was linked to multiple positive outcomes. The process of developing insight also linked to aspects of increasing self-worth, since this led to increased self-awareness, understanding of others and ultimately more mutually supportive relationships. Relief, increasing self-worth and insight are all categories which have also emerged from qualitative research into clients' views of significant events in therapy (see Timulak, 2003). Enhancing coping strategies, to regulate emotions such as anger, proved useful for some clients. Finally, some clients used the counselling relationship as an opportunity to practise and improve on the skills involved in open relating, both expressing and receiving. These clients were then able to exercise these skills with greater confidence in their significant relationships.

All of these clients went through helpful change processes in SBHC, and talking about their emotions was pivotal to achieving positive change in the domains of self, relationships, emotions and functioning. This was partly facilitated by counsellor behaviours which emerged as helpful factors and included advice, activities, questions and general talking. In this study, counsellors offered activities such as relaxation techniques in response to a client's needs, representing a more directive end of the humanistic counselling spectrum. It is worth noting that what is labelled 'advice' in this and previous studies, based on the terminology used by clients, may be more likely to be described as 'process guidance' in the humanistic field. These behaviours appear to serve a dual function for clients: they are helpful in their own right (for example, in learning to cope with emotions or developing insight), and they can facilitate the development of the counselling relationship by putting clients at ease. This encourages open discussion of emotions, a practice which for young people in their everyday lives appears to be both therapeutic and unusual. 
The processes emerging from the analysis of this data indicate that multiple concomitant pathways of change are possible, which is a core tenet of the pluralistic approach to counselling articulated by Cooper and McLeod $(2007 ; 2012)$. The same positive changes were achieved by different clients in different ways, and a range of processes were experienced as helpful. It seems likely that individual differences play a large role in determining how change is achieved in counselling, such as personality factors, age and gender. For instance, the process of enhancing coping strategies was only evident for young males in this study. It may also be that in this study, differences between schools could have played a role in how young people perceived and engaged with counselling. Furthermore, change processes associated with different theories of personality change were not mutually exclusive. For instance, clients who appreciate counsellor directivity in the form of activities may also experience a process of increasing self-worth brought about by the counsellor's attitude to them in the relationship. Similar processes may have different outcomes depending on the individual client and the same outcome can be achieved through different processes: some clients improve their relationships through developing their insight while others achieve the same goal by enhancing their coping strategies. Different processes of change overlap, demonstrating that progression in SBHC does not follow a single, predictable route.

A first limitation of this study is that there was no opportunity to check participants' reactions to the analysis. Hence, the study has low testimonial validity (Stiles, 1993). Second, participants experienced one form of therapeutic intervention only. Hence, while their responses are indicative of the kinds of change processes that may take place in SBHC, they cannot be understood as exhaustive for school-based counselling more generally. Third, the sample does not include a wide range of different young people, partly because data was taken from a randomised controlled trial which employed distress-related inclusion and 
exclusion criteria for participation, and was set in a single geographical area with little ethnic diversity. Fourth, the theoretical orientation of the authors, as well as the nature of the counselling intervention, potentially biases the results towards humanistic change processes. Using a data-driven approach goes some way towards addressing this bias: meaning units were extracted on the basis of what clients said, without reference to specific research questions. However, the first author's interpretation of the data is key, and potentially subject to humanistic bias. In addition, young people may have been primed to report experiences in line with this model, since they had experienced humanistic therapy. Having said this, the presence of disconfirming evidence supports the credibility of the analysis, since the results do not support a purely humanistic approach. Finally, the sample size was determined by the available data and therefore may not have reached saturation point.

A key implication of these findings for the practice of SBHC is that incorporating more counsellor-led activities can help young people to cope and to develop insight. For some humanistic counsellors, this may contradict a stance of principled non-directivity. Further research should explore client and counsellor perspectives on what constitutes directivity and its therapeutic potential. The study also highlights the positive impact of a valuing and understanding attitude towards young clients, and suggests that such an attitude can be communicated in different ways, which may include counsellor-led activities. These findings suggest that counsellor training, instead of focusing on a single therapeutic model, may benefit from exploration of alternative processes of change and developing counsellors' ability to tailor their work to individual clients.

\section{Conclusion}


Pathways to change for young people in SBHC include relief, increasing self-worth, developing insight, enhancing coping strategies and improving relational skills. Positive changes are experienced by young people in the domains of relationships, self, emotions and functioning. Talking openly about emotions is a central benefit of school-based counselling for young people, and this can be facilitated through the counsellor's personal qualities and independence from the client's life, directive activities, and a therapeutic relationship characterised by liking, comfort and trust. The counsellor's attitude of respectful attention and valuing was shown to be healing, supportive of the client's self-worth and linked to helpful insights. Learning skills and applying behavioural techniques was also helpful, especially in relation to coping with emotions.

\section{References}

Bondi, L., Forbat, L., Gallagher, M., Plows, V., \& Prior, S. (2006). Evaluation of the youth counselling service. University of Edinburgh.

Christens, B.D. \& Peterson, N.A. (2012). The role of empowerment in youth development: A study of sociopolitical control as mediator of ecological systems' influence on developmental outcomes. Journal of Youth and Adolescence, 41(5): 623-635.

Cooper, M. (2004). Counselling in schools project: Evaluation report. Glasgow: Counselling Unit, University of Strathclyde.

Cooper, M. (2009). Counselling in UK secondary schools: A comprehensive review of audit and evaluation data. Counselling and Psychotherapy Research, 9(3), 137-150. 
Cooper, M. (2013). School-based counselling in UK secondary schools: A review and critical evaluation. Lutterworth:BACP/Counselling MindEd. Download from www.counsellingminded.com .

Cooper, M., \& McLeod, J. (2007). A pluralistic framework for counselling and psychotherapy: Implications for research. Counselling and Psychotherapy Research, 7, 135-143.

Cooper, M., Rowland, N., McArthur, K., Pattison, S., Cromarty, K. \& Richards, K. (2010). Randomised controlled trial of school-based humanistic counselling for emotional distress in young people: Feasibility study and preliminary indications of efficacy. Child and Adolescent Psychiatry and Mental Health, 4, 1-12. doi: 10/1186/1753-2000-4-12.

Cooper, M. \& McLeod, J. (2012). From either/or to both/and: Developing a pluralistic approach to counselling and psychotherapy. European Journal of Psychotherapy \& Counselling, 14(1), 5-17.

Department for Education (2015). Counselling in Schools: a blueprint for the future. Departmental advice for school leaders and counsellors.

Department of Health (2015). Future in Mind: Promoting, protecting and improving our children and young people's mental health and wellbeing.

Elliott, R. (1999). Client change interview protocol. Network for Research on Experiential Psychotherapies; available from http://experiential-researchers.org/instruments/elliott/ changei.html. 
Elliott, R., Fischer, C. \& Rennie, D.L. (1999). Evolving guidelines for publication of qualitative research studies in psychology and related fields. British Journal of Clinical Psychology, 38, 215-229.

Glaser, B.G. \& Strauss, A. (1967). The discovery of grounded theory: Strategies for qualitative research. Chicago: Aldine.

Glaser, B.G. (1978). Theoretical sensitivity: Advances in the methodology of grounded theory. Mill Valley, CA: The Sociology Press.

Griffiths, G. (2013). A systematic review of young people's experiences of helpful and unhelpful factors in school-based counselling. (Unpublished thesis). University of Strathclyde and Glasgow Caledonian University, UK.

Hanley, T., Barlow, A., Humphrey, N., Jenkins, P. \& Wigelsworth, M. (2012). A scoping review of the access to secondary school counselling, Lutterworth: BACP internal document.

Hill, A., Cooper, M., Pybis, J., Cromarty, K., Pattison, S., Spong, S., ... Maybanks, N. (2011). Evaluation of the Welsh school-based counselling strategy. Cardiff: Welsh Government Social Research.

Hill, A., Roth, A., \& Cooper, M. (2014). The competences required to deliver effective humanistic counselling for young people. Lutterworth: BACP. Retrieved from http:// www.bacp.co.uk/research/resources/cyp_competences.php

Kovacs, M. (1997). Depressive disorders in childhood: An impressionistic landscape. Journal of Child Psychology and Psychiatry, 38, 287-298.

Lynass, R., Pykhtina, O., \& Cooper, M. (2012). A thematic analysis of young people's experience of counselling in five secondary schools in the UK. Counselling and Psychotherapy Research, 12(1), 53-62. 
McArthur, K., Cooper, M. \& Berdondini, L. (2013). School-based humanistic counseling for psychological distress in young people: Pilot randomized controlled trial. Psychotherapy Research, 23(3), 355-365. doi:10.1080/10503307.2012.726750.

McArthur, K. (2014). Effectiveness, Process and Outcomes in School-Based Humanistic Counselling. Unpublished PhD thesis. University of Strathclyde.

McLeod, J. (2001). Qualitative research in counselling and psychotherapy. London: Sage. McKenzie, K., Murray, G.C., Prior, S. \& Stark, L. (2011). An evaluation of a school counselling service with direct links to child and adolescent mental health (CAMH) services. British Journal of Guidance and Counselling, 39(1), 67-82.

Ogden, N. (2006). Interviews with clients regarding the impact of counselling on their studying and learning. In M. Cooper, Counselling in Schools Project Phase II: Evaluation report. Glasgow: Counselling Unit, University of Strathclyde. Available at http://strathprints.strath.ac.uk/26793/.

Pybis, J., Cooper, M., Cromarty, K., Hill, A., Levesley, R., Murdoch, J. \& Turner, N. (2014). Small scale randomised controlled trial of school-based counselling for psychological distress in young people: Outcomes and methodological reflections. Counselling and Psychotherapy Research. doi:10.1080/14733145.2014.905614.

Rennie, D.L., Phillips, J.R. \& Quartaro, G.K. (1988). Grounded theory: A promising approach to conceptualization in psychology? Canadian Psychology, 29, 139-150.

Rennie, D.L. (1990). Towards a representation of the client's experience of the psychotherapy hour. In G. Lietaer, J. Rombauts \& R. Van Balen (Eds.), Clientcentered and experiential therapy in the nineties (pp. 155-172). Leuven, Belgium: Leuven University Press. 
Roth, A., Hill, A., \& Pilling, S. (2009). The competences required to deliver effective humanistic psychological therapies. University College London.

Rupani, P., Haughey, N. \& Cooper, M. (2012). The impact of school-based counselling on young people's capacity to study and learn. British Journal of Guidance and Counselling, 40(5), 499-514.

Schwabe, L. \& Wolf, O.T. (2010). Learning under stress impairs memory formation. Neurobiology of Learning and Memory, 93(2), 183-188.

Stiles, W.B. (1993). Quality control in qualitative research. Clinical Psychology Review, 13, 593-618.

Timulak, L. (2003). Empowerment events in process-experiential psychotherapy of depression: An exploratory qualitative analysis. Psychotherapy Research, 13(4), $443-460$.

Timulak, L. (2007). Identifying core categories of client identified impact of helpful events in psychotherapy. A qualitative meta-analysis. Psychotherapy Research, 17, 305-314. 